\title{
Percepção dos colaboradores de uma equipe de enfermagem quanto ao estilo de liderança de seu superior imediato
}

\author{
Perception of nursing team contributors about the leadership style of yours \\ immediate superior
}

\author{
Andressa Schaurich dos Santos ${ }^{1}$ \\ Vânia Medianeira Flores Costa ${ }^{2}$ \\ Gean Carlos Tomazzoni ${ }^{3}$ \\ Laércio André Gassen Balsan ${ }^{4}$ \\ Stefania Tonin ${ }^{5}$
}

\begin{abstract}
Resumo
Este estudo tem como objetivo verificar a percepção dos colaboradores da equipe de enfermagem quanto ao estilo de liderança de seu superior imediato e comparar a forma como esses se desenvolvem em instituições hospitalares públicas e privadas. Para tanto, realizou-se uma pesquisa descritiva, de caráter quantitativo. A população do estudo foi composta por enfermeiros, técnicos e auxiliares de enfermagem. Para a análise dos dados, utilizou-se o cálculo de estatísticas descritivas (tabelas de frequências, medidas de tendência central, medidas de dispersão e padronização das médias dos construtos). Os resultados indicaram que os gestores, tanto nos hospitais públicos quanto nos privados, apresentam um nível alto para a liderança transformacional e mediano para a liderança transacional. Entretanto, apesar de haver um predomínio do estilo transformacional, em geral, a atuação do superior como líder se destaca quando existem problemas a serem resolvidos. Além disso, os resultados verificados nesta pesquisa demonstram ser possível a coexistência dos estilos de liderança transacional e transformacional, os quais não são abordagens opostas, mas contribuem uma com a outra para o bom desempenho organizacional.
\end{abstract}

Palavras chave: Estilos de Liderança. Enfermagem. Instituições Hospitalares.

\begin{abstract}
This study aims to determine the perception of nursing staff employees about the leadership style of his immediate superior and compare how these develop in public and private hospitals. For this purpose, was carried out a quantitative descriptive approach. The study population consisted of nurses, technicians and nursing assistants. For data analysis was used to calculate descriptive statistics (frequency tables, measures of central tendency, measures of dispersion and standardization of the means of constructs). The results indicated that managers in both hospitals, public and private, have a high level for transformational leadership and median to transactional leadership. However, although there was a predominance of transformational style, in general, the role of the superior as leader stands out when there are problems to be solved. In addition, the results obtained in this research demonstrate possible the coexistence of styles of transactional and transformational leadership, which are not opposite approaches but contribute to each other for good organizational performance.
\end{abstract}

Keywords: Leadership Styles. Nursing. Hospital Institutions.

Doutoranda em Administração - Programa de Pós-graduação em Administração da Universidade Federal de Santa Maria - PPGA/UFSM. Brasil. Afiliação: Universidade Federal de Santa Maria. Lattes: http://lattes.cnpq.br/2247093929888265 Email: dessaschaurich@gmail.com

2 Doutorado em Administração pela Universidade Federal da Bahia (2008). Brasil. Afiliação: Universidade Federal de Santa Maria. Lattes: http:// lattes.cnpq.br/0180563343119839 Email: vaniaflores2006@yahoo.com.br

3 Doutorando do Programa de Pós-Graduação em Administração da Universidade Federal do Rio Grande do Sul. Brasil. Afiliação: Universidade do Rio Grande do Sul. Lattes: http://lattes.cnpq.br/7556533304392951 Email: gean.tomazzoni@hotmail.com

4 Doutorado em Administração pela Universidade Federal de Santa Maria (2017). Brasil. Afiliação: Universidade Federal de Santa Maria. Lattes: http://lattes.cnpq.br/0191047014576061 Email: laerciobalsan@yahoo.com.br

5 Doutoranda em Administração pela Universidade Federal de Santa Maria, UFSM. Brasil. Afiliação: Universidade Federal de Santa Maria. Lattes: http://lattes.cnpq.br/9046167215415373 Email: stefaniatonin@gmail.com 


\section{Introdução}

Há muito tempo a liderança tem sido amplamente estudada por diferentes áreas sob a tutela de campos específicos de conhecimento e da prática profissional (CALAÇA; VIZEU, 2015). Com o passar dos anos, surgiram novas formas de abordagens para compreender como os líderes se comportam em relação aos seus subordinados, refletindo em diversos estudos, os quais, segundo Hoch (2013) e Van Prooijen e Vries (2016), revelam que o estilo de liderança adotado pelo líder é um dos mais importantes determinantes da eficácia das equipes de trabalho e do desempenho organizacional.

No entendimento de Avolio et al. (2003), embora as características pessoais do líder influenciem na condução do grupo, é o comportamento e o estilo de gestão que serão decisivos para o resultado final da interação. Assim, foi desenvolvida uma abordagem que integrou os aspectos comportamentais e os traços de personalidade, reconciliando algumas controvérsias dos estudos sobre liderança das últimas décadas, originando duas novas teorias: a transacional e a transformacional.

Moscon (2013) reconhece que o comportamento dos gestores depende de diversas variáveis, como o ambiente onde a relação líder e liderado se desenvolve. Segundo a autora, cada contexto de trabalho apresenta características específicas que irão impactar na forma como se desenvolve esse construto, trazendo importantes contribuições para uma análise mais aprofundada dos significados desse fenômeno para os sujeitos envolvidos na relação líder e liderado.

Frente ao exposto, este estudo se insere em instituições de saúde, mais especificamente nas organizações hospitalares. Conforme destacam Borba e Kliemann Neto (2008), os hospitais se apresentam como um setor rico em experiências e práticas de gestão. Entretanto, poucos ainda são os estudos desenvolvidos por pesquisadores que analisam essas abordagens. De acordo com Zoboli (2002), dentre as organizações empresariais, essas são as empresas que assumem maior complexidade, devido à ampla articulação necessária para a gama de recursos, elementos e dispositivos que devem ser alinhados de modo coordenado às ações de ensino, assistência e pesquisa.

Para Teixeira et al. (2006), um modo de entender o hospital é vê-lo como uma organização de características próprias, que o diferenciam de outras instituições. Contemporaneamente, os hospitais são instituições prestadoras de serviço (BONATO, 2003), cuja principal característica que os diferenciam das demais empresas é a natureza do seu trabalho, que é dirigido para aliviar o sofrimento e a preservar a saúde e a vida. Portanto, compreender a atividade hospitalar como um negócio, não esquecendo a sua função social, exige uma gestão empresarial ética e desafiadora.

No entendimento de Pillon (2011), um dos desafios impostos aos hospitais se refere aos processos gerenciais, existindo a necessidade de alinhá-los aos cuidados em saúde, de modo que esse tenha eficiência e qualidade. Atualmente, muitos hospitais vivem um dilema: a necessidade de modernizar as formas de trabalho em contraposição a uma cultura organizacional arcaica (CAMPOS; BONASSA, 2006); destacando-se, assim, a importância do papel da liderança nesse cenário de quebra de paradigmas e adequação às novas necessidades do mercado.

Diante desse palco, fica evidente o papel do enfermeiro enquanto responsável pela gerência dos serviços e do cuidado em saúde (LIMA, 2013). Conforme ressaltam Lourenço e Trevizan (2001) e Rodrigues e Lima (2004), a gestão em enfermagem abrange um conjunto de atividades gerenciais e assistenciais que são caracterizadas pelo exercício da liderança, sendo essa uma ferramenta imprescindível no processo de trabalho do enfermeiro.

Assim, ao considerar que o serviço de enfermagem: (a) é a principal categoria profissional (em termos quantitativos) que faz as instituições de saúde produzirem serviços (SANTOS, 2007); (b) possui elevado grau de autonomia em relação à direção, gerenciando o dia a dia das unidades assistenciais e possuindo, internamente, uma linha de comando vertical formalizada e legitimada (CECÍLIO, 1999); e (c) depende da liderança para a melhoria da qualidade do trabalho e da assistência prestada ao paciente (HIGA; TREVIZAN, 2005), cabendo ao enfermeiro o gerenciamento da assistência de enfermagem, bem como o desenvolvimento de atividades administrativas, coloca-se a seguinte questão de pesquisa: Como se manifesta o estilo de liderança de gestores da equipe de enfermagem tanto em instituições hospitalares 
públicas quanto privadas? Para responder tal questionamento, este estudo objetivou verificar a percepção dos colaboradores da equipe de enfermagem quanto ao estilo de gestão de seu superior imediato e comparar a forma como esses se desenvolvem em instituições hospitalares públicas e privadas.

A relevância do estudo se materializa ao proporcionar elementos teóricos e empíricos de um tema ainda pouco explorado dentro do contexto de trabalho pesquisado. O artigo apresenta questões específicas de como se desenvolve a liderança nos hospitais públicos e privados, trazendo importantes contribuições para uma análise mais aprofundada dos significados envolvidos na relação líder e liderado, levando a uma reflexão sobre estratégias que possibilitam uma melhor gestão da categoria de profissionais analisada.

\section{Liderança e estilos de gestão}

Quando se inicia um estudo sobre a temática de liderança, percebe-se que muito se pesquisa sobre o assunto, porém, não existe um consenso quanto a sua definição, sendo difícil determinar com precisão o que é ser "líder" e o que é "liderança". Na visão de Bass (1990, p.4), "existem quase tantas definições de liderança quanto pessoas a tentar defini-la". Apesar de o termo possuir uma diversidade de conceitos, para Northouse (2004), quatro componentes podem ser identificados como fundamentais na compreensão do fenômeno: trata-se de um processo, o qual envolve uma influência, ocorre em um contexto grupal, e, para o alcance de determinadas metas. O fato de se constituir em um processo, segundo Moscon (2013), implica em entender que não é uma característica que reside no líder, e sim que afeta e é afetado pela relação que se estabelece com a equipe.

Em conformidade com essa ideia, Spector (2006) afirma que o pensamento comum que faz parte de várias definições diz que liderança envolve: influenciar as atitudes, crenças, comportamentos e sentimentos de outras pessoas. Assim, no entendimento de Calaça e Vizeu (2015), nos estudos chamados pelos autores de gerencialistas - aqueles com orientação acadêmico-científica que visam aprimorar a prática de gestão das organizações -, a liderança está fortemente vinculada à eficiência produtiva, tendo como pressuposto fundamental a capacidade de líderes e seus subordinados de atingirem os resultados organizacionais.

Partindo das explanações acima descritas, conforme Macêdo et al. (2007, p. 110), é possível identificar o líder como aquela pessoa que "no exercício de qualquer função de comando permanente ou temporária, formalmente designada ou não, é capaz de influenciar a equipe e, sendo por ela legitimado, representá-la e conduzi-la numa determinada situação". Além disso, para os autores, é importante destacar ainda que, a liderança requer, inevitavelmente, o uso do poder para influenciar os pensamentos e ações dos outros.

Segundo Barreto et. al (2013), os trabalhos iniciais sobre o tema buscavam identificar as características, os traços e o comportamento do líder. A partir do final da década de 90 , o foco dos estudos passou a abordar a liderança como um processo de influenciar os indivíduos dentro de uma cultura organizacional e a relação interativa entre líder e seguidor. Nesse cenário, desenvolveram-se e disseminaram-se novas teorias de liderança para reconciliar algumas controvérsias apresentadas por estudos anteriores. Dentre essas novas teorias, destacam-se: as teorias da liderança transacional e transformacional, que surgiram pela primeira vez nas pesquisas de Burns (1978 apud VIZEU, 2011), com a proposta de integrar diversas abordagens, aspectos comportamentais e traços de personalidade. Essa proposta realizada, além de pioneira, foi considerada a de maior influência sobre os pesquisadores, uma vez que foi a partir desse contexto que outras importantes proposições se desenvolveram (VIZEU, 2011).

De acordo com Marquis e Huston (1999), Burns sustentou que há dois tipos de líderes: o tradicional, preocupado com as operações do dia a dia, chamado de transacional, e o comprometido, visionário e capaz de distribuir responsabilidades, chamado de transformacional. Porém, segundo Calaça e Vizeu (2015), apesar de ter sido Burns o precursor da distinção entre líderes transacionais e transformacionais, foi Bass que popularizou seu estudo na literatura gerencialista, de tal forma que esse modelo é reconhecido pelos pesquisadores de liderança em organizações como uma das mais importantes abordagens da "nova liderança" que surgiu em contraponto à perspectiva contingencial.

A liderança transacional, segundo Bass (1990), refere-se às trocas estabelecidas no relacionamento entre líder e liderado, cuja finalidade é satisfazer os interesses de ambos. Para Gomes e Cruz (2007) e 
Walumbwaet al.(2008), este líder baseia sua ação na legitimidade e autoridade formais, enfatizando regras e normas estabelecidas pelos superiores e focando a atenção para o cumprimento das tarefas previamente definidas. Sobral e Peci (2008) ainda ressaltam que esse líder guia seus subordinados em direção aos objetivos pretendidos e distribui recompensas para aqueles que conseguem alcançá-las. Já aqueles cujo desempenho se mostra aquém do esperado são punidos (AVOLIO et al., 2009). Vizeu (2011) explica que, não há no modelo transacional uma preocupação com a coletividade, ou com princípios moralmente determinados. Esse estilo enfatiza o autointeresse (seja dos seguidores, seja do líder).

Por sua vez, na liderança transformacional, segundo Burns (1978 apud VIZEU, 2011) e Aryee et al.(2012), os líderes inspiram moralmente seus seguidores, estimulando o desenvolvimento de necessidades de autorrealização e comprometimento com valores e interesses coletivos. Notavelmente, para Zacher et al. (2014), líderes transformacionais buscam atender às necessidades dos indivíduos a fim de desenvolvê-los. Eles criam motivação intrínseca e fazem com que os indivíduos percebam os objetivos organizacionais como sendo seus (AVOLIO et al., 2009; ZHANG; WANG, 2017), gerando um desempenho acima do esperado (MARQUES et al., 2007). Além disso, Muniz Filho (2013) evidencia que os líderes transformacionais são proativos e inovadores, não se contentando em alcançar um desempenho "dentro das expectativas". Essa teoria pode ser mensurada em quatro componentes: carisma ou influência idealizada, motivação inspiracional, estimulação intelectual e consideração individualizada.

Além dessas dimensões relacionadas às teorias da liderança transacional e transformacional, Bass e Avolio (1992 apud Northouse, 2004) tratam ainda do que denominam ausência de liderança (laissezfaire). Nessa dimensão, segundo os autores, não se observa a troca entre líderes e subordinados, ou seja, o líder ignora a sua responsabilidade, não assume os objetivos definidos, e adia a tomada de decisões importantes, não dando suporte nem desenvolvendo sua equipe. De acordo com Araújo (2011), Bass enfatiza que os dois tipos de liderança são processos distintos; entretanto, podem ser complementares.

Segundo Marquis e Huston (1999), embora o líder transformacional seja considerado o "ideal", autores como Bass, Avolio e Goodhein (1987) advertem que deve ser acompanhado de qualidades de líderes transacionais. Para os autores, o líder transformacional irá fracassar sem as habilidades tradicionais presentes nos transacionais. Logo, ambos os grupos de características precisam estar presentes no mesmo indivíduo; gerando, a partir disso, um desempenho para além das expectativas. Morhart et al. (2009) também abordam essa situação em seu estudo e sugerem que esses estilos coexistem com sucesso. Inclusive, certo nível de liderança transacional pode aumentar a liderança transformacional, e vice-versa.

\section{Equipe de enfermagem e liderança do enfermeiro}

De acordo com Pianucci (2005), a prática de enfermagem em equipe é norteada por um enfermeiro, profissional qualificado e registrado no órgão regulamentador do exercício da profissão, COFEN, que atua como líder, tomando as decisões em relação ao atendimento de enfermagem. Já os membros da equipe - técnicos e auxiliares de enfermagem - estão sob supervisão daquele profissional, devendo cumprir e assumir seu papel profissional, colaborando com o líder para que se alcancem os objetivos propostos para a equipe $\mathrm{e} o$ atendimento aos clientes.

Para a autora, o maior objetivo do trabalho em equipe na enfermagem é proporcionar assistência contínua e de qualidade a quem está sendo cuidado. Sendo assim, é necessário planejar e sistematizar a assistência, visando desenvolver cuidados que suprirão as necessidades humanas básicas afetadas do cliente. Nesse contexto, insere-se o papel de liderança que o profissional enfermeiro ocupa nas instituições de saúde.

Do mesmo modo como é difícil tratar do tema liderança em qualquer área, desenvolver um trabalho sobre essa questão na enfermagem também se constitui uma tarefa complicada. A liderança, nesse contexto, de acordo com Gelbcke et al. (2009), é objeto de pesquisas sob diferentes perspectivas, principalmente no sentido de incorporá-la como aliada no seu cotidiano. Para tanto, o agir com liderança se torna uma tarefa cada vez mais árdua, exigindo melhores resultados, inovação e crescimento constantes; sendo, segundo os autores, uma ferramenta imprescindível no processo de trabalho do enfermeiro. 
De acordo com Rozendo e Gomes (1998), o enfermeiro seria um elemento importante para "fazer funcionar" a instituição, especialmente através de atividades de controle e orientação dos colaboradores do seu setor, por meio da função de supervisão. Nesse sentido, a figura do enfermeiro ocupa papel de destaque, pois é o responsável pela condução do pessoal de enfermagem, servindo de elo entre os "superiores" e os "subordinados".

Lima e Binsfeld (2003) destacam que uma breve observação sobre o dia a dia do trabalho do enfermeiro hospitalar é suficiente para perceber que o seu trabalho é prevalentemente administrativo, embora isso não se dê por opção, mas por uma certa imposição da administração hospitalar, que espera que o mesmo se responsabilize pelo bom funcionamento das unidades. No entendimento de Pereira (2007), a prática da liderança de enfermagem não deve estar somente em consonância com a instituição, mas também voltada para as condições de trabalho e as necessidades dos profissionais da equipe.

\section{Método}

Foi realizada uma pesquisa descritiva, de caráter quantitativo, em duas instituições hospitalares localizadas na cidade de Porto Alegre/RS, uma pertencente ao setor público e a outra ao privado, denominadas nessa pesquisa de Hospital A e Hospital B, respectivamente. Essas duas organizações foram escolhidas por serem hospitais de grande porte e de referência no atendimento médico-hospitalar de alta complexidade.

\subsection{Participantes da pesquisa}

A amostra foi calculada por meio de uma fórmula para população finita, optando-se pela técnica de amostragem probabilística aleatória. Foi considerado um erro amostral de $5 \%$ e um nível de confiança de $95 \%$. Diante disso, obteve-se como amostra necessária para pesquisa um total de 342 participantes. Todavia, obteve-se um retorno um pouco superior ao valor determinado pelo cálculo amostral, totalizando 347 respondentes.

A maior concentração dos participantes da pesquisa pertence à instituição pública, totalizando 190 pesquisados $(54,76 \%)$; enquanto que; na organização privada; tem-se um total de 157 respondentes (45,24\%). Participaram da pesquisa 81 enfermeiros, sendo 46 do Hospital A (público) e 35 do Hospital B (privado), e 263 técnicos/auxiliares de enfermagem, sendo 142 do Hospital Ae 121 do Hospital B. Desses, a maioria são mulheres (83,28\%), em sua maioria (41,91\%) com idade entre 26 e 35 anos de idade, são casadas $(37,03 \%)$ e com um filho $(51,33 \%)$. Em termos ocupacionais, observa-se a prevalência das profissionais com $2^{\circ}$ grau completo/Técnico (53,73\%), tempo de profissão de 11 a 20 anos (30,81\%) e tempo de atuação na organização de 1 a 5 anos (57,66\%). Quando se analisa essas informações por tipo de instituição, verifica-se a maior porcentagem, de $20,66 \%$, na faixa de 11 a 20 anos para o Hospital A (público) e 16,86\% na faixa de até 5 anos para o Hospital B (privado). Sendo assim, é possível afirmar que os profissionais da organização privada possuem menos tempo de carreira que os da instituição pública. $O$ mesmo constata-se em relação ao tempo de serviço.

Por fim, quanto à remuneração, 44,19\% dos profissionais recebem de 1 a 3 salários mínimos, seguidos dos que ganham de 4 a 6 (39,53\%). Do total, 47,38\% divide igualmente a responsabilidade financeira da família com outra pessoa. Analisando essas informações por tipo de hospital, percebe-se que, de acordo com o exposto pelos participantes, os colaboradores da equipe de enfermagem do Hospital A (público) são melhores remunerados que os do Hospital B (privado). Se somarmos as porcentagens das faixas de 4 até mais de 10 salários mínimos na instituição pública, têm-se $43,61 \%$ da renda dos pesquisados, enquanto que a mesma porcentagem $(43,61 \%)$ para a instituição privada concentra-se nas faixas de 1 a 6 salários mínimos.

\subsection{Instrumento}

Utilizou-se um questionário, com itens fechados, composto de duas partes. A primeira parte do questionário era composta de 12 questões visando obter os dados de identificação dos respondentes, 
tais como: idade, sexo, escolaridade, estado civil, número de filhos, tipo de instituição hospitalar, função, unidade de trabalho/turno/carga horária semanal, tempo de profissão/carreira, período de atuação na organização, responsabilidade pela manutenção da família e renda salarial. Já a segunda parte, composta por 21 questões, teve por objetivo identificar os estilos de liderança através da escala MLQ Form 6S, proposto por Bass e Avolio (1992 apud NORTHOUSE, 2004) e traduzida e adaptada para o contexto brasileiro por Moscon (2013).

Cabe ressaltar que as 21 questões da segunda parte estão divididas nos três estilos de liderança, conforme segue: 6 itens da liderança transacional, que refere-se às trocas estabelecidas no relacionamento entre líder e seguidos, cuja finalidade é satisfazer os interesses de ambos (BASS, 1990); 12 itens da liderança transformacional, que representa a capacidade do líder em conseguir que o liderado transcenda seus próprios interesses em favor da organização e tenha um desempenho extra papel (MARQUES et al., 2007); e 3 itens da ausência de liderança, na qual o líder abre mão ou ignora a sua responsabilidade, não assume objetivos definidos e adia a tomada de decisões importantes, não se observando troca entre líderes e subordinados nem empenho do líder em dar suporte e desenvolver a sua equipe (MOSCON, 2013).

\subsection{Coleta de dados}

Após a aprovação pelo Comitê de Ética da Universidade (Protocolo CEP-UFSM: 788.478; CAAE 34690314.7.0000.5346), o projeto foi encaminhado às duas organizações hospitalares coparticipantes da pesquisa para avaliação dos seus respectivos comitês de ética. Somente após a autorização dos três comitês a coleta de dados foi iniciada.

Essa foi realizada no período compreendido entre outubro e dezembro de 2014. Cada participante foi abordado individualmente, ou em pequenos grupos, no seu próprio local de trabalho, sendo informado sobre do que se tratava a pesquisa. Nesse momento, também foram esclarecidas possíveis dúvidas ou dificuldades de compreensão do questionário. Ao estar de acordo em integrar o estudo e, após assinar o TCLE, entregou-se o instrumento de pesquisa e foi acordada uma data para seu recolhimento.

\subsection{Análise de dados}

A análise dos dados foi realizada quantitativamente com o auxílio dos softwares Microsoft Excel, versão 2010, e Statistical Analysis System (SAS), versão 9.1. Para identificar os níveis dos estilos de liderança, realizou-se análise bivariada, com cálculos de estatística descritiva (tabelas de frequências, medidas de tendência central e de dispersão e padronização das médias dos construtos e das dimensões) e o teste de Mann-whitney, para verificar as diferenças entre os níveis dos estilos de liderança das equipes de enfermagem de hospitais públicos e privados, bem como a diferença dos estilos de liderança entre os enfermeiros e o grupo formado por técnicos e auxiliares de enfermagem. Optou-se pelo teste não paramétrico, uma vez que os dados se demonstraram assimétricos durante a inspeção de histogramas. Consideraram-se estatisticamente significantes os testes com um $p<0,05$.

Com o propósito de identificar os níveis dos estilos de liderança, os dados intervalares foram transformados em dados categóricos por meio de procedimentos de Cluster Analysis. A categorização dos dados levou em conta o cálculo da média das respostas dos indivíduos em relação à escala Likert de 5 pontos, utilizada no instrumento de pesquisa, definindo-se o parâmetro para a classificação dos clusters a partir do escore padronizado (MALHOTRA, 2012). Assim, obtiveram-se as seguintes categorias em relação às médias padronizadas: alto (de 66,67 a 100), médio (de 33,34 a 66,66) e baixo (de 0 a 33,33). Essa padronização teve o intuito de esclarecer o nível atingido por cada construto utilizado no presente estudo.

\section{Resultados e discussão}

Na tabela 1 são apresentadas as médias obtidas para os construtos de maneira geral e por tipo de instituição, bem como o teste de Mann-Whitney. 
Tabela 1 - Estatística dos Estilos de Liderança.

\begin{tabular}{l|c|c|c|c|c|c|c}
\hline \multirow{2}{*}{ Estilos de Liderança } & \multicolumn{2}{|c|}{ GERAL } & \multicolumn{2}{c|}{$\begin{array}{c}\text { HOSPITAL A } \\
\text { (PÚBLICO) }\end{array}$} & \multicolumn{2}{c|}{$\begin{array}{c}\text { HOSPITAL B } \\
\text { (PRIVADO) }\end{array}$} & \multirow{2}{*}{ p-valor } \\
\cline { 2 - 8 } & Média & $\begin{array}{c}\text { Desvio } \\
\text { Padrão }\end{array}$ & Média & $\begin{array}{c}\text { Desvio } \\
\text { Padrão }\end{array}$ & Média & $\begin{array}{c}\text { Desvio } \\
\text { Padrão }\end{array}$ & \\
\hline Liderança Transacional & 66,22 & 12,36 & 64,96 & 12,46 & 67,69 & 12,07 & $\mathrm{p}=0,035^{*}$ \\
\hline Liderança Transformacional & 68,30 & 14,93 & 66,33 & 15,57 & 70,63 & 13,79 & $\mathrm{p}=0,003^{*}$ \\
\hline Ausência de Liderança & 46,03 & 16,25 & 43,88 & 15,24 & 48,56 & 17,02 & $\mathrm{P}=0,015^{*}$ \\
\hline
\end{tabular}

${ }^{*} \mathrm{p}<0,05$

Fonte: Dados da pesquisa

Referente à liderança transacional, verifica-se que o valor para a média geral foi de 66,22 , sendo classificado como de nível médio. Contudo, cabe salientar que esse é próximo de ser classificado como alto (de 66,67 à 100). Essa mesma classificação mediana se mantém quando analisada a média do Hospital A $(64,96)$, enquanto que, para o Hospital B, classifica-se com nível alto $(67,69)$. Logo, pode-se inferir que os participantes da pesquisa do hospital privado visualizam seus líderes com um índice mais elevado de liderança transacional do que os pesquisados do hospital público. Tais resultados precisam ser vistos com cautela, uma vez que, mesmo categorizados em níveis diferentes, a diferença entre as médias é pequena.

Em relação à liderança transformacional, a média geral foi igual a 68,30 , muito próximo a classificação alta. Quando considera-se a análise dos hospitais em separado, no Hospital B esse estilo é classificado como de nível alto $(70,63)$, enquanto que, para o Hospital A, é classificado como nível mediano $(66,33 \%)$.

Referente à análise da última dimensão dos estilos de liderança, denominada ausência de liderança, o valor verificado para a média geral foi de 46,03 , sendo classificado como um nível médio para essa amostra. Essa mesma classificação média se mantém para os casos do Hospital A e B $(43,88$ e 48,56, respectivamente).

Diante dos resultados expostos, verifica-se que liderança transacional se apresenta para o contexto de estudo, de forma geral, com um nível médio, sendo que esse estilo representa uma troca formal entre líder e liderado com o objetivo de satisfazer a necessidade de ambos. Ainda pode-se afirmar que os indivíduos do hospital privado visualizam seus líderes com um índice mais elevado de liderança transacional do que os pesquisados no hospital público. Tal fato indica que nos hospitais privados os lideres conseguem de maneira mais efetiva fazer com que seus subordinados transcendam seus próprios interesses em favor da organização. Além disso, os resultados parecem demostrar que o superior imediato atua de forma mais efetiva como líder no momento de resolução de problemas, ou seja, tendem a gerenciar pela "exceção", além de fornecer feedback aos liderados quando acontece o erro.

No que se refere à liderança transformacional e suas dimensões é possível afirmar que essa se apresenta, para a amostra em geral, como sendo de nível alto, indicando que o líder representa um modelo que desperta admiração, respeito e confiança.

O estudo de Gonçalves (2008), em cinco instituições hospitalares, sobre os estilos de liderança por meio da autopercepção do enfermeiro gestor também evidenciou escores muito mais elevados para a liderança do tipo transformacional. Santos (2012) também evidenciou, em uma instituição hospitalar uma maior liderança transformacional entre os gestores pesquisados. Constatou-se ainda que, os pesquisados da instituição privada percebem seus superiores como altamente transformacionais, enquanto que os da instituição pública como medianamente transformacionais. Tal fato indica que, para o Hospital B, os líderes inspiram moralmente seus liderados, atuando como um exemplo para os subordinados.

Por fim, em relação à ausência de liderança, observou-se menores valores para as escalas que medem os estilos de gestão dos superiores, demonstrando que os pesquisados acreditam mais fortemente que possuem líderes em suas organizações, seja com estilo transacional ou transformacional. Esses achados corroboram com o encontrado nos estudos de Gonçalves (2008), Santos (2009) e Moscon (2013), que obtiveram também baixos índices de ausência de liderança para os seus contextos de estudo. 
Santos (2009) encontrou em uma pesquisa com enfermeiros gestores de hospitais públicos e privados de Portugal, que os mesmos consideram aplicar de maneira mais efetiva em seu cotidiano de gestão uma liderança mista, do que puramente transformacional, e pouco se utilizam da ausência de liderança. Em outro estudo, realizado por Gonçalves (2008), os estilos de liderança dos enfermeiros gestores apresentaram frequências elevadas para o estilo transformacional, seguindo o transacional e com frequência baixa ou ausente para o estilo ausência de liderança. Além desses, Moscon (2013) também obteve uma percepção favorável dos pesquisados em relação aos seus líderes, tanto na dimensão transformacional quanto na transacional, apoiando o que Bass (1990) já afirmara: que os melhores líderes são, ao mesmo tempo, transacionais e transformacionais.

O líder transacional é aquele mais centrado nas tarefas administrativas e no estabelecimento de normas e regras, com o intuito de satisfazer tanto as necessidades dos indivíduos quanto da organização. Já o superior transformacional está mais voltado à descentralização de poderes, delegando tarefas e sendo baseado na confiança e no auto desenvolvimento. Essa liderança, para Bass (1990), é a única modalidade que propicia aos seguidores um desempenho extraordinário ao procurar elevar a consciência do grupo e da empresa, favorecendo a evolução das pessoas e alinhando às expectativas individuais e organizacionais.

Contudo, conforme consta da revisão de literatura, de acordo com Araujo (2011), as lideranças transacional e transformacional são processos distintos, entretanto, complementares. Segundo Marquis e Huston (1999), apesar do líder transformacional ser o "ideal", é necessário que seja acompanhado de qualidades transacionais para ter um desempenho além das expectativas.

Como forma de complementar as análises em relação ao objetivo deste estudo, apresenta-se na tabela 2 os níveis dos construtos de liderança em relação aos cargos de enfermeiros e técnicos/auxiliares de enfermagem por instituição pública e privada, através da análise da frequência, evidenciando-se convergências e/ou divergências na percepção desses profissionais.

Tabela 2 - Nível de Estilos de liderança por categoria profissional e tipo de instituição

\begin{tabular}{|c|c|c|c|c|c|c|}
\hline \multicolumn{7}{|c|}{ LIDERANÇA TRANSACIONAL (\%) } \\
\hline \multirow{2}{*}{ FUNÇÃO } & \multicolumn{2}{|c|}{ BAIXO } & \multicolumn{2}{|c|}{ MÉDIO } & \multicolumn{2}{|c|}{ ALTO } \\
\hline & Público & Privado & Público & Privado & Público & Privado \\
\hline Enfermeiro & 0,00 & 0,00 & 67,44 & 31,43 & 32,56 & 68,57 \\
\hline Téc./Aux. Enfermagem & 1,47 & 0,85 & 50,74 & 40,68 & 47,79 & 58,47 \\
\hline \multicolumn{7}{|c|}{ LIDERANÇA TRANSFORMACIONAL (\%) } \\
\hline \multirow{2}{*}{ FUNÇÃO } & \multicolumn{2}{|c|}{ BAIXO } & \multicolumn{2}{|c|}{ MÉDIO } & \multicolumn{2}{|c|}{ ALTO } \\
\hline & Público & Privado & Público & Privado & Público & Privado \\
\hline Enfermeiro & 6,82 & 2,86 & 56,82 & 22,86 & 36,36 & 74,28 \\
\hline Téc./Aux. Enfermagem & 2,21 & 1,69 & 35,29 & 27,97 & 62,50 & 70,34 \\
\hline \multicolumn{7}{|c|}{ AUSÊNCIA DE LIDERANÇA (\%) } \\
\hline \multirow{2}{*}{ FUNÇÃO } & \multicolumn{2}{|c|}{ BAIXO } & \multicolumn{2}{|c|}{ MÉDIO } & \multicolumn{2}{|c|}{ ALTO } \\
\hline & Público & Privado & Público & Privado & Público & Privado \\
\hline Enfermeiro & 9,30 & 17,14 & 83,72 & 80,00 & 6,98 & 2,86 \\
\hline Téc./Aux. Enfermagem & 16,91 & 11,02 & 77,94 & 74,57 & 5,15 & 14,41 \\
\hline
\end{tabular}

Fonte: Dados da pesquisa

A partir do observado na tabela 2, ambas as categorias profissionais apresentam um nível médio (enfermeiros $67,44 \%$; técnicos/auxiliares $50,74 \%$ ) de liderança transacional no hospital público, sendo que no privado grande parte da amostra apresentou um nível alto (enfermeiros 68,57\%; técnicos/auxiliares $58,47 \%$ ). Esses achados corroboram com os resultados evidenciados anteriormente, parecendo ser correto afirmar que enfermeiros e técnicos/auxiliares da organização privada classificam seus líderes como mais transacionais que os do hospital público. 
Em relação à liderança transformacional, grande parte dos enfermeiros do hospital público classificam seus superiores com um médio nível de liderança transformacional $(56,82 \%)$, à medida que enfermeiros do hospital privado percebem seus líderes com um nível alto para esse estilo de gestão $(74,28 \%)$. Em relação à categoria técnicos/auxiliares de enfermagem, em ambas as instituições o nível obtido foi alto (62,50\% hospital público; $70,34 \%$ hospital privado). Da mesma forma, os dados apresentados corroboram com o exposto nas análises anteriores, que evidenciaram um maior nível de liderança transformacional no hospital privado, mas não havendo tanta diferença para o público.

Por fim, acerca da ausência de liderança, verificam-se os maiores percentuais para ambos os cargos no nível mediano para o construto, sendo os percentuais dos enfermeiros (público $83,72 \%$; privado $80 \%$ ) ligeiramente superiores ao dos técnicos/auxiliares de enfermagem (público 77,94\%; privado 74,57\%). A partir disso, parece ser correto afirmar que técnicos/auxiliares de enfermagem dos hospitais públicos e privados percebem suas lideranças como de forma mais positiva que os enfermeiros dessas instituições.

Complementando a análise, ao se comparar as percepções dos enfermeiros com a dos técnicos/ auxiliares de enfermagem, 0 teste de Mann-Whitney foi significativo para os construtos liderança transacional $(p=0,031)$, liderança transformacional $(p=0,003)$ e ausência de liderança $(p=0,0252)$. Tal resultado demonstra que os enfermeiros tem uma percepção diferenciada de seus superiores, daquela tida sobre eles por seus subordinados (técnicos/auxiliares de enfermagem).

Acredita-se que essa constatação deu-se devido aos enfermeiros assumirem o papel de líder perante técnicos/auxiliares que coordenam nas unidades, fazendo com que esses os considerem como tal. Contudo, esses enfermeiros muitas vezes não consideram os seus superiores imediatos como verdadeiros gestores, corroborando com o nível mais alto de ausência de liderança percebida por essa categoria.

\section{Conclusão}

Diante de todas as constatações, conclui-se que, na percepção dos pesquisados, ambos os hospitais possuem líderes. Contudo, no hospital privado, essa liderança (tanto transacional quando transformacional) é verificada como sendo um pouco mais forte do que no hospital público. Cabe ressaltar também que os resultados verificados nesta pesquisa demonstram ser possível a coexistência dos estilos de liderança transacional e transformacional, os quais não são abordagens opostas, mas contribuem uma com a outra para o bom desempenho organizacional, cabendo ao gestor usar os diferentes estilos de liderança a depender da situação vivenciada.

Neste estudo, a equipe de enfermagem participante da pesquisa classificou seus superiores como medianamente transacionais, sendo que esse estilo se apresentou mais fortemente como uma troca formal entre líder e liderado, com o objetivo de satisfazer a necessidade de ambos. Ademais, o superior imediato nessas instituições atua mais como um líder quando existem problemas, ou seja, gerenciam pela "exceção", além de o feedback aos liderados ocorrer apenas quando acontece o erro. Quando se analisou as instituições separadamente, os pesquisados do hospital privado classificaram seus superiores com um índice mais elevado de liderança transacional do que os do hospital público, indicando que os lideres nos hospitais privados inspiram mais seus subordinados do que nos hospitais públicos.

Já no que se refere à liderança transformacional a equipe de enfermagem dos hospitais pesquisados classificaram seus líderes como altamente transformacionais, sendo que esse estilo se sobressaiu em um modelo que desperta admiração, respeito e confiança dos liderados pelos superiores.

No que compete à ausência de liderança, os resultados indicaram um nível médio, sendo esse o menos evidenciado entre os estilos. Essa constatação reforçou a avaliação positiva da equipe de enfermagem dos hospitais pesquisados quanto à maneira de gestão de seus superiores. Assim pode-se dizer que esses acreditam ter líderes em suas organizações, sejam esses transacionais ou transformacionais.

Constatou-se ainda que, os técnicos e auxiliares de enfermagem percebem suas lideranças de forma mais positiva que os enfermeiros dessas instituições. Essa constatação se deu devido ao fato de os enfermeiros assumirem o papel de líder perante técnicos/auxiliares que coordenam nas unidades, fazendo 
com que esses os enxerguem como tal. Todavia, esses mesmos enfermeiros muitas vezes não visualizam os seus superiores imediatos como verdadeiros gestores.

Acredita-se que a presente pesquisa traz importantes contribuições para o meio científico e para a área de comportamento organizacional. Fundamentalmente, como forma de contribuir com o aumento de investigações acerca dos estilos de liderança nas organizações e da possibilidade de poder tratar os construtos transacional e transformacional como complementares. Além disso, outra ênfase está no fato de ser um estudo em instituições de saúde, públicas e privadas, e com a equipe de enfermagem que, além de fornecer subsídios para a gestão dessas, ajuda a compreender como se dá a percepção desses quanto à liderança nesses contextos de estudo e com essa categoria profissional específica.

Entretanto, esse estudo não pode deixar de apontar seus limites, sendo uma das principais limitações a ausência de estudos sobre os estilos de liderança em equipes de enfermagem, dificultando a comparação dos achados obtidos com outras pesquisas sobre o tema envolvendo a categoria de profissionais e suas organizações. Destaca-se como aspecto limitador também o campo de estudo restrito a duas instituições hospitalares. Assim, sugere-se para estudos futuros uma investigação com uma amostra ampliada tanto em termos regionais e nacionais, que possam oferecer uma maior generalização dos resultados.

Apesar dessas limitações, por se tratar de um estudo inicial para a categoria de profissionais analisada, este trabalho apresenta aspectos essenciais à compreensão de um tema de grande importância, abrindo espaço para a formulação de novas possibilidades e hipóteses de pesquisas. Ao finalizar esse estudo, espera-se que o mesmo contribua para o desenvolvimento de reflexões que propiciem novos direcionamentos à gestão dessa categoria de profissionais, bem como para o meio científico, colaborando com o avanço de pesquisas na área e conduzindo a novos direcionamentos relacionados aos temas aqui abordados.

\section{Referencias}

ARAÚJO, J. M. C. Influência da Liderança Transformacional na confiança e Comprometimento organizacionais. 2011. 121 f. Dissertação (Mestrado em Gestão das Organizações) - Instituto Politécnico do Porto, Universidade do Porto, Porto. 2011

AVOLIO, B. J.; WALUMBWA, F. O.; WEBER, T. J. Leadership: current theories, research, and future directions. Annual Review of Psychology, [S.I], v. 60, p. 421-449, 2009.

AVOLIO, B. J. et. al. Leadership models, methods, and applications. In: WEINER, I. B. et.al. (Eds.). Handbook of psychology: industrial and organizational psychology. New Jersey: John Wiley \& Sons, Inc., 2003, p. 367-389.

BARRETO, L. M. T. S. et. al. Cultura organizacional e liderança: uma relação possível? Revista de Administração da USP, São Paulo, v. 48, n. 1, p. 34-52, jan./fev./mar. 2013.

BASS, B. M.; AVOLIO, B. J.; GOODHEIM, L. Biography and the assessment of transformational leadership at the world class level. Journal of Management, [S.I], v. 13, n.1, p. 7-19, Marc. 1987.

BASS, B. Two Decades of Research and development in Transformational Leadership. European Journal of Work and Organizational psychology, [S.I], v. 8, n. 1, p. 9-32, 1990.

BONATO, V. L. Programas de qualidade em hospitais do município de São Paulo. 2003. 206 f. Tese (Doutorado em Administração) - Universidade de São Paulo, São Paulo. 2003.

BORBA, G. S.; KLIEMANN NETO, F. J. Gestão hospitalar: identificação das práticas de aprendizagem existentes em hospitais. Saúde e Sociedade, São Paulo, v. 7, n. 1, p. 44-60, 2008.

CALAÇA, P. A.; VIZEU, F. Revisitando a perspectiva de James MacGregor Burns: qual é a ideia por trás do conceito de liderança transformacional? Cadernos EBAPE.BR, Rio de Janeiro, v. 13, n 1, p. 121-135, jan/.mar. 2015. 
CAMPOS, C. V. A.; BONASSA, E. C. O novo paradigma da gestão de pessoas. In: GONÇALVES, E. L. Gestão Hospitalar: administrando o hospital moderno. São Paulo: Saraiva, 2006, p. 92-108.

CECÍLIO, L. C. O. Uma sistematização e discussão de tecnologia leve de planejamento estratégico aplicada ao setor governamental. In: MERHY, E.; ONOCKO, R. (Org.). Agir em Saúde São Paulo: Hucitec, 1997, p. 161-168.

GOMES, A. R.; CRUZ, J. Abordagem carismática e Transformacional: modelos conceptuais e contributos para o exercício da liderança. Psicologia USP, São Paulo, v. 18, n. 3, p. 143-161, set. 2007.

GONÇALVES, M. N. C. Estilos de liderança: um estudo de auto-percepção de enfermeiros gestores. 2008. 129 f. Dissertação (Mestrado em Ciências Empresariais) - Universidade Fernando Pessoa, Porto. 2008.

HIGA, E. F. R.; TREVIZAN, M. A. Os Estilos de liderança idealizados pelos enfermeiros. Revista LatinoAmericana de Enfermagem, Ribeirão Preto, v. 13, n. 1, p. 59-64, jan./fev. 2005.

$\mathrm{HOCH}$, J. E. Shared leadership and innovation: The role of vertical leadership and employee integrity. Journal of Business and Psychology, [S.I], v. 28, p. 159-174, Jun. 2013.

LIMA, J. C.; BINSFELD, L. O trabalho do enfermeiro na organização hospitalar: núcleo operacional autônomo ou assessoria de apoio ao serviço médico? Revista de Enfermagem da UERJ, Rio de Janeiro, v. 11, p. 98-103, 2003.

LIMA, M. P. Comprometimento e entrincheiramento com a carreira de enfermeiros: uma análise dos vínculos em instituições hospitalares públicas e privadas. 2013. 196 f. Dissertação (Mestrado em Administração) - Universidade Federal de Santa Maria, Santa Maria. 2013.

LOURENÇO, M. R.; TREVIZAN, M. A. Líderes de enfermagem brasileira: sua visão sobre a temática da liderança e sua percepção a respeito da relação liderança e enfermagem. Revista

Latino-Americana de Enfermagem, São Paulo, v. 9, n. 3, p. 14-19, maio 2001.

MACÊDO, I. I et al. Aspectos Comportamentais da Gestão de Pessoas. Rio de Janeiro: Editora FVG, 2007.

MALHOTRA, N. Pesquisa de marketing: uma orientação aplicada. Porto Alegre: Bookman, 2012.

MARQUES, G. M. et al. Estilos de liderança e comprometimento organizacional: uma aplicação do multifactor leadership questionnaire (MLQ) no Brasil. Adm. MADE, Rio de Janeiro, v. 11, n. 2, p. 99-125, maio/ ago. 2007.

MARQUIS, B. L.; HUSTON, C. J. Administração e liderança na enfermagem: teoria e aplicação. Porto Alegre: Artmed, 1999.

MORHART, F. M.; HERZOG, W.; TOMCZAK, T. Brand-Specific leadership: turning employees into brand champions. Journal of Marketing, [S.I], v. 73, n. 5, p. 122-142, Sep. 2009.

MOSCON, D. C. B. As relações entre liderança e estabelecimento de vínculos do trabalhador nas organizações. 2013. 154 f. Tese (Doutorado em Administração) - Universidade Federal da Bahia, Salvador. 2013.

MUNIZ FILHO, S. M. S. Os efeitos do estilo de liderança no comprometimento organizacional dos profissionais de tecnologia da informação. 2013. 90 f. Dissertação (Mestrado em Gestão Empresarial) - Fundação Getúlio Vargas, Rio de Janeiro. 2013

NORTHOUSE, P. G. Leadership: theory and practice. Thousand Oaks: Sage Publications, 2004.

PEREIRA, E. B. A liderança na enfermagem em oncologia e os nexos com a humanização: uma perspectiva dos líderes. 2007. 174 f. Dissertação (Mestrado em enfermagem) - Universidade Federal do Rio de Janeiro, Rio de Janeiro. 2007. 
PIANUCCI, A. M. G. C. Saber cuidar: procedimentos básicos em enfermagem. São Paulo: SENAC, 2005.

PILLON, R. B. F. Planejamento estratégico de um hospital universitário: Um estudo de caso no hospital universitário da UFSM. 2011. 144 f. Dissertação (Mestrado em Administração) - Universidade Federal de Santa Maria, Santa Maria. 2011

RODRIGUES, F. C. P.; LIMA, M. A. D. S. A multiplicidade de atividades realizadas pelo enfermeiro em unidades de internação. Revista Gaúcha de Enfermagem, Porto Alegre (RS), v. 25, n. 3, p. 314-322, dez. 2004.

ROZENDO, C. A.; GOMES, E. L. R. Liderança na enfermagem brasileira: aproximando-se de sua desmitificação. Revista Latino-Americana de Enfermagem, [S.I], v. 6, n. 5, p. 67-76, dez. 1998.

SANTOS, D. L. Análise da relação entre o comprometimento e a aprendizagem organizacional: um estudo em uma organização hospitalar. 2009. 129 f. Dissertação (Mestrado em Administração) Universidade Federal de Santa Maria (RS), Santa Maria (RS). 2009.

SANTOS, M. M. R. Liderança transformacional e transacional numa organização de saúde: a questão do género. 2012. 208 f. Dissertação (Mestrado em Gestão dos Serviços de Saúde) - Instituto Universitário de Lisboa, Lisboa. 2012.

SANTOS, S. R. Administração aplicada à enfermagem. João Pessoa: Ideia, 2007.

SOBRAL, F.; PECI, A. Administração: teoria e prática no contexto brasileiro. São Paulo: Pearson Prentice Hall, 2008.

SPECTOR, P. E. Psicologia nas Organizações. São Paulo: Saraiva, 2006.

TEIXEIRA, J. M. C. et al. Planejamento estratégico e operacional em saúde. São Paulo: Saraiva, 2006.

VAN PROOIJEN, J.; VRIES, R. E. Organizational conspiracy beliefs: implications for leadership styles and employee outcomes. Journal of Business and Psychology, [S.I], v. 31, n.4, p. 479-491, Dez.2016.

VIZEU, F. Uma aproximação entre liderança transformacional e teoria da ação comunicativa. Revista de Administração Mackenzie, São Paulo, v. 12, n. 1, p. 53-81, jan./fev. 2011.

WALUMBWA, F. O.; WU, C.; ORWA, B. Contingent reward transactional leadership, work attitudes, and organizational citizenship behavior: the role of procedural justice climate perceptions and strength. Leadership Quarterly,[S.I], v. 19, n. 3, p. 251-265, Jun. 2008.

ZACHER, $\mathrm{H}$. et al. Leaders' personal wisdom and leader-member exchange quality: the role of individualized consideration. Journal of Business Ethics, [S.I], v. 121, n. 2, p. 171-187, May 2014.

ZHANG, L.; CAO, T.; WANG, Y. The mediation role of leadership styles in integrated project collaboration: an emotional intelligence perspective. International Journal of Project Management, v.36, n.2, p. 317330, Nov. 2017.

ZOBOLI, L. C. P. Ética e administração hospitalar. São Paulo: Centro Universitário São Camilo, 2002.

Submetido em: 26/10/2017

Aprovado em: 13/12/2017 